\title{
Review
}

\section{Laminectomy for cervical myelopathy}

\author{
NE Epstein*,1,2,3,4 \\ ${ }^{I}$ The Albert Einstein College of Medicine, Bronx, NY, USA; ${ }^{2}$ The North Shore-Long Island Jewish Health System, \\ Manhasset, NY, USA; ${ }^{3}$ New Hyde Park, NY, USA $;{ }^{4}$ Winthrop University Hospital, Mineola, NY, USA
}

Study design: Cervical laminectomy with or without fusion, or laminoplasty, successfully address congenital or acquired stenosis, multilevel spondylosis, ossification of the posterior longitudinal ligament (OPLL), and ossification of the yellow ligament (OYL). To optimize surgical results, however, these procedures should be applied to carefully selected patients.

Objectives: To determine the clinical, neurodiagnostic, appropriate posterior cervical approaches to be employed in patients presenting with MR- and CT-documented multilevel cervical disease. To limit perioperative morbidity, dorsal decompressions with or without fusions should be performed utilizing awake intubation and positioning and continuous intraoperative somatosensoryevoked potential monitoring.

Setting: United States of America.

Methods: The clinical, neurodiagnostic, and varied dorsal decompressive techniques employed to address pathology are reviewed. Techniques, including laminectomy, laminoforaminotomy, and laminoplasty are described. Where preoperative dynamic X-rays document instability, simultaneous fusions employing wiring or lateral mass plate/screw or rod/screw techniques may be employed. Nevertheless, careful patient selection remains one of the most critical factors to operative success as older individuals with prohibitive comorbidities or fixed long-term neurological deficits should not undergo these procedures.

Results: Short- and long-term outcomes following dorsal decompressions with or without fusions vary. Those with myelopathy over 65 years of age often do well in the short-term, but demonstrate greater long-term deterioration. Factors that correlated with greater susceptibility to deterioration include advanced age ( $>70$ years at the time of the first surgery), severe original myelopathy, and recent trauma.

Conclusions: Success rates of laminectomy with or without fusion, or laminoplasty may be successfully employed to address multilevel cervical pathology in a carefully selected population of patients.

Spinal Cord (2003) 41, 317-327. doi:10.1038/sj.sc.3101477

Keywords: cervical laminectomy; laminoplasty; posterior fusion; wiring; lateral mass; screws

\section{Introduction}

Cervical laminectomy remains a useful operative alternative for the management of cervical myelopathy where the cervical lordotic curvature is well-preserved. This is particularly true in the geriatric age group where comorbidities increase operative risk. Cervical laminectomy may address congenital or acquired stenosis, multilevel spondylosis, select cases of ossification of the posterior longitudinal ligament (OPLL), and ossification of the yellow ligament (OYL). Chronic olisthy or frank instability may be selectively and simultaneously addressed with varied posterior stabilization procedures.

*Correspondence: N Epstein, Long Island Neurosurgical Associates, 410 Lakeville Rd. Suite 204, New Hyde Park, NY 11042, USA
Anatomy and pathophysiology

Absolute stenosis is defined by a canal measuring $10 \mathrm{~mm}$ in anterior/posterior dimension, while relative stenosis denotes a $13 \mathrm{~mm}$ canal. ${ }^{1}$ Both radicular and myelopathic complaints arise when the canal is narrowed to these critical dimensions as the cord itself occupies between 0.8 and $1.3 \mathrm{~cm}$ in the anterior/posterior dimension, and soft tissues take up another $2-3 \mathrm{~mm} .^{2}$ Disc herniations, spurs, OPLL, and OYL further compromise the already narrowed space, increasing the likelihood of incurring a significant neurological deficit even with minor traumatic events especially extension. Direct mechanical trauma and indirect ischemia contribute to neurological dysfunction. Gray and white matter damage associated 
with cord atrophy, demyelination, and infarction are often located several segments above or below the site of maximal cord compromise. ${ }^{3}$

\section{Clinical parameters and neurological grading}

Patients with absolute cervical stenosis develop radicular or myelopathic complaints in their 40s-50s, while those with relative stenosis present more typically in their 50s and 60s. ${ }^{4-10}$ Patients with lumbar stenosis over 65 years of age should routinely have cervical studies performed as $10 \%$ of these individuals will have significant tandem cervical stenosis. ${ }^{11}$ For these patients with myeloradiculopathy, male usually outnumber female patients - 2:1. Radicular complaints include pain, numbness, tingling, or weakness in a specific or varied dermatomal distribution. Myelopathy, usually painless, is characterized by upper and lower extremity weakness, numbness, and loss of balance.

Myelopathy is evaluated with several grading systems: Nurick Grades, Japanese Orthopedic Association Score, and Ranawat Scores. The Nurick Grades are as follows: Grade 0 - intact, Grade 1 - mild myelopathy, Grade II mild-to-moderate myelopathy, Grade III - moderate myelopathy, Grade IV - moderate-to-severe myelopathy, and Grade V - severe myelopathy. ${ }^{5-10}$ The Japanese Orthopedic Association Score assigns 17 points to upper and lower extremity function. ${ }^{12,13}$ The Ranawat System, devised particularly for those with rheumatoid arthritis, employs four grades, Grades I, II, IIIA, and III B, the latter reflecting severe quadriparesis or quadriplegia.

\section{Preoperative myelopathic deficits}

Patients undergoing cervical laminectomy usually exhibit moderate-to-severe preoperative myelopathy (Nurick Grades III-IV). This is characterized by atrophy of the thenar and hypothenar eminence, stereoanesthesia, the 'useless hand syndrome', and proximal lower extremity weakness. Other findings include diffuse hyperreflexia accompanied by bilateral Babinski responses, a relative level to pin prick from C5 downward with loss of vibratory and position appreciation with the inability to walk in a tandem fashion.

\section{Differentiation from neurodegenerative disorders}

Neurodegenerative disorders that must be differentiated from cervical spondylotic myelopathy or OPLL-related myelopathy include multiple sclerosis (MS), amyotrophic lateral sclerosis (ALS), paraneoplastic syndromes, and toxic-metabolic disorders (diabetes, alcoholism, vitamin $\mathrm{B}_{12}$ deficiency). ${ }^{14}$ Magnetic resonance imaging scans, cerebrospinal fluid studies, serum studies, peripheral nerve or muscle biopsies, and electromyographic evaluations help determine whether these syndromes are present. Other entities such as diffuse idiopathic skeletal hyperostosis (DISH) may also contribute to or coexist with OPLL-related myelopathy. ${ }^{15}$

\section{Biomechanics of laminectomy}

Flexion and extension maneuvers alter the space available to the spinal cord and nerve roots. ${ }^{2,16}$ Flexion, by increasing axial tension, narrows the AP diameter of the cord, while extension shortens and thickens the cord dimensions. Hyperextension in a congenitally stenotic spinal canal with hyperlordosis, results in inward shingling of the laminae and infolding of hypertrophied or ossified yellow ligament both of which may further contribute to significant dorsal cord compression. Laminectomy in this setting immediately increases the space available for the spinal cord, and results in improved cord perfusion as axial tension is released.

\section{Biomechanics of facet resection}

Differing degrees of facet resection may contribute to instability following laminectomy. Typically, stability is maintained following resection of less than $25 \%$ of the medial aspect of the facet joint. ${ }^{17}$ However, 50, 75 and $100 \%$ of facet joint resection results in successively greater degrees of instability as confirmed in both biomechanical and clinical studies. ${ }^{18-23}$

\section{Neurodiagnostic studies}

Cervical stenosis may be determined through 'Gestalt' techniques or by using direct measurements on plain Xray alone. If the anterior margin of the facet joints overlaps the interlaminar line, the canal is congenitally stenotic. If the vertebral body in its anteroposterior dimension cannot 'fit' within the spinal canal, the canal is congenitally narrowed. Alternatively, one may directly calculate the anterior-posterior measurements of the vertebral canal, and create a ratio of the two confirming the finding of stenosis.

Dynamic X-rays Dynamic X-rays help define whether patients have sufficient lordosis to undergo laminectomy for stenosis successfully. On static or dynamic films, a minimal lordotic curvature of $10^{\circ}$ is required if laminectomy is to be performed, which sufficiently allows the cord to migrate away from ventrally situated osteophytes or OPLL. ${ }^{12}$ Candidates for laminectomy or laminoplasty should exhibit at least $10^{\circ}$ of lordosis and less than $7 \mathrm{~mm}$ of ventral OPLL or spondylosis. ${ }^{24}$ Where laminoplasty is to be considered, a minimum of $14 \mathrm{~mm}$ of anterior-posterior decompression should be feasible for those with CSM compared with a greater $17 \mathrm{~mm}$ for those with OPLL. ${ }^{25}$

Frank instability is defined on flexion/extension studies by more than $3.5 \mathrm{~mm}$ of subluxation, greater than $20^{\circ}$ of angulation, and over $1-2 \mathrm{~mm}$ of motion demonstrated between the tips of adjacent spinous processes.

$M R$ MR readily defines spinal cord and nerve root compression as well as other intrinsic cord abnormalities both preoperatively and postoperatively in multiple planes. ${ }^{1,14,26-28}$ Cerebrospinal fluid remains hypointense 
on T1-weighted studies, while the cord appears isointense. T2-weighted studies create a 'myelographic' image as CSF becomes hyperintense, while the cord itself stays hypointense. Increased cord signals on T2 images indicate demyelination, edema, or myelomalacia, and constitute poorer prognostic findings for patients with spondylotic myelopathy compared with those exhibiting OPLL. Those with severe, irretrievable cord damage should not be considered surgical candidates as their chances for recovery are minimal. ${ }^{26}$

Shortcomings of MR include the inability to visualize bony pathology directly. Bone will appear hypointense, creating a negative image, often underestimating the true extent of cervical spondylosis or OPLL.

Dynamic MR Dynamic MR studies may further document spinal cord compression not readily visualized on static studies. Preoperatively, ventral compression from spurs or OPLL and dorsal intrusion from shingled laminae, infolded hypertrophied or ossified yellow ligament, accompanied by instability/olisthy may be seen. Following laminectomy, dynamic MR scans may demonstrate foci of residual cord compromise, reversal of the lordosis, or kyphosis not appreciated on

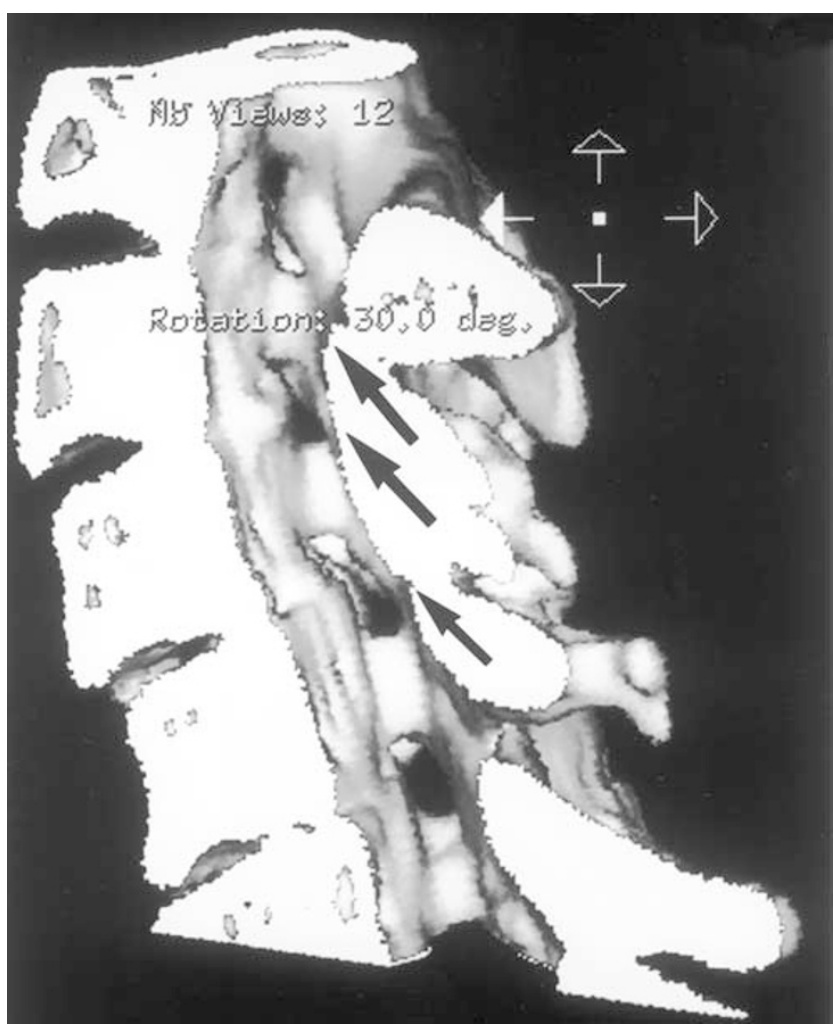

Figure 1 Preoperative midline sagittal 3D-CT study demonstrates congenital cervical stenosis with an AP canal diameter of less than $10 \mathrm{~mm}$ from C3 to C7. Note, shingling of the laminae (single arrows) contributing to marked dorsal-lateral cord compression static studies. Employing dynamic MR, Morimoto et al ${ }^{29}$ found that 5 years postlaminectomy, a 37-year-old male required a $\mathrm{C} 4-\mathrm{C} 7$ anterior corpectomy and fusion for further progression of OPLL intruding on the cord in flexion studies.

CT CT directly documents the calcification, ossification, and configuration of cervical bony pathology . CT, myeloCT, 2D- and 3D-CT studies demonstrate in multiple planes, the conformation of the cervical spinal canal (Figures 1 and 2). In particular, the transaxial myelo-CT provides better detail regarding foraminal pathology than the MR. However, if the cord is severely compromised and the increased signal in the cord corresponds with active cord compression rather than long-standing myelomalacia, a myelo-CT may be contraindicated as this may risk acute neurological deterioration. Rather, 2D- or 3D-CT studies should be employed.

Conservative treatment of cervical stenosis

Management of mild cervical stenosis or even more severe stenosis in the elderly who are not considered surgical candidates is performed usually by neurologists and pain center specialists. Treatment modalities include cervical collars, short-term steroidal and long-term nonsteroid anti-inflammatory medications, physical therapy, biofeedback techniques, and occasional epidural steroid injections. ${ }^{30-33}$ Occasional patients with mild myelopathy, despite MR scans showing increased cord signals, may be successfully managed with various traction methods and cervical bracing techniques. ${ }^{34}$

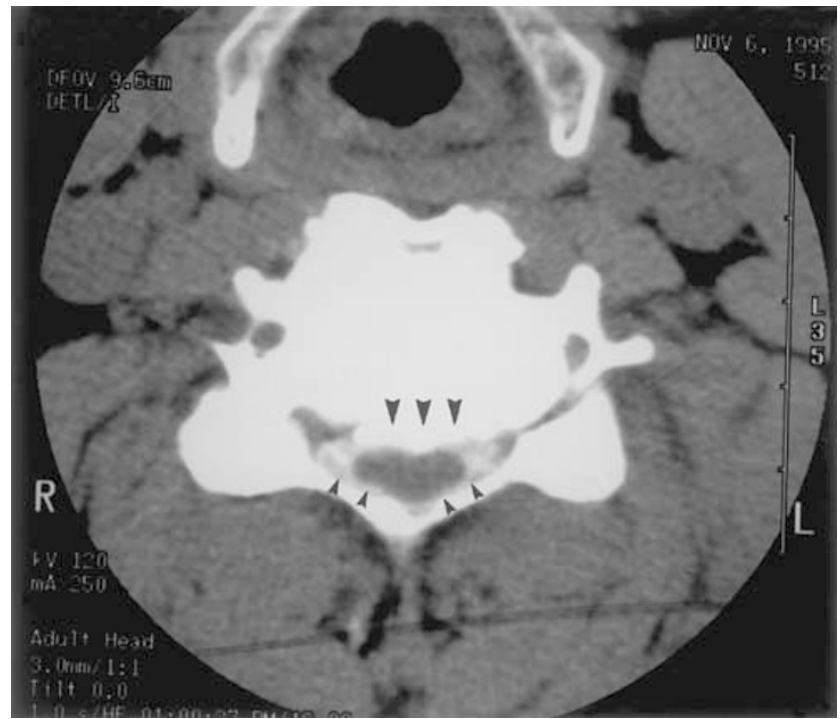

Figure 2 Trans-axial myelo-CT examination shows congenital stenosis, ventral OPLL (triple arrows), and dorsal-lateral laminar shingling (double arrows) contributes to multilevel cord compression 


\section{Preventative cervical decompression}

There are few critical indications for considering prophylactic cervical surgery. Patients under 65 years of age, if mildly symptomatic or at risk for quadriplegia with even mild trauma, may warrant early decompression. However, for patients 65-70 years of age, increased comorbid factors substantially increase the risk of prophylactic decompression. Poor prognostic factors found in multiple studies include advanced age $(>70$ years old), cardiac disease, peripheral vascular disease, obstructive pulmonary disease, diabetes, stroke, hypertension, and alcoholism. ${ }^{9,10,35}$ Older individuals with these comorbid factors, if considered for surgery, require preoperative diagnostic studies that may include nuclear stress testing, pulmonary function studies, carotid and/or arterial lower extremity doppler studies, and others. Patients on anticoagulation or on antiplatelet aggregants because of mechanical cardiac valves, a history of TIA or stroke, unstable atrial fibrillation, active myo-cardial or peripheral vascular arterial or venous disease must be encouraged to seek nonsurgical alternatives for the management of their cervical myelopathic syndromes.

\begin{abstract}
Anesthesia
Nasotracheal or endotracheal fiberoptic intubation, awake positioning, and continuous intraoperative somatosensoryevoked potential monitoring are employed for patients with significant cervical cord compression undergoing laminectomy. With the patient immobilized in a hard cervical collar, Q-tips coated with neosynephrine are first placed in the nasopharynx through the larger nares. The nares is successively dilated with larger nasal trumpets coated with $0.5 \%$ Xylocaine Jelly. Prior to fiberoptic placement of the endotracheal tube, a transtracheal injection of $5 \mathrm{~cm}^{3}$ of injectable $1 \%$ Lidocaine HCL may also be utilized. If an endotracheal procedure is performed, the patient may suck on a tongue blade coated with $1 \%$ Lidocaine Jelly or gargle with aerosolized lidocaine. Next, a fiberoptic cable passed through a wirereinforced anode tube (ie $7.5 \mathrm{~mm}$ ) is threaded through the vocal cords under direct vision. The balloon is inflated just above the carina and the tube is taped in situ. Lidocaine $0.5 \%$ with epinephrine $1: 200,000$ is then injected $\left(5 \mathrm{~cm}^{3}\right.$ per injection) at the three pin sites of the Mayfield head holder. With the hard collar in place, the patient is then turned prone. For the next $5 \mathrm{~min}$ in the prone posture, the neurological examination is checked, while SSEPS are studied to make sure that baselines have been maintained. Undue flexion or extension in the three-pin-head holder or poor operative positioning of the shoulders, arms, or hands may result in SSEP decrement or loss; correction of any one of these problems prior to induction is critical. Arterial line monitoring is used to maintain the blood pressure usually $20 \%$ above the norm, avoiding hypo-tension. A foley catheter is placed to monitor urinary output. Patients are also prophylactically administered $1 \mathrm{gm}$ of intravenous methylprednisolone for cord 'protection'.
\end{abstract}

Monitoring of cervical surgery Intraoperative somatosensory-evoked potential monitoring includes the noninvasive assessment of median or ulnar, and posterior tibial function throughout surgery. ${ }^{36}$ Significant changes are defined by a greater than $50 \%$ loss of amplitude or greater than $10 \%$ prolongation of latency. Medical resuscitative measures that address deterioration include: increased oxygenation, decreased inhalation or intravenous anesthetic, warming of irrigating solutions, induction of hypertension, and the addition of peroxide. Surgical resuscitative measure include: the release of distraction, removal of an over-sized graft resulting in undue cord traction, and cessation of manipulation. Note that false positives are treated as 'mini-true positives' requiring adjustment of technique and the institution of medical or surgical resuscitative maneuvers. Motor-evoked potentials may also be employed intraoperatively in addition to SSEPs as they help to monitor anterior cord function directly. Intraoperative electromyographic monitoring (EMG) is employed during focal root manipulation as well as during any stabilization procedure.

Operative positioning The pros of using the sitting position for laminectomy include reduced intraoperative bleeding particularly in obese patients with short thick necks, easier intraoperative ventilation for those with pulmonary disease, and greater accessibility for cardiac massage should cardiac arrest occur. The cons of the seated posture may outweigh the pros, including the greater risk of air embolism, hypotension, stroke, and cord ischemia, particularly in older individuals with significant cardiovascular pathology. ${ }^{37-39}$

\section{Laminectomy}

The laminectomy is performed by injecting the skin and paracervical musculature with $0.5 \%$ Bupivicaine HCL with 1:200,000 epinephrine $\left(30 \mathrm{~cm}^{3}\right)$. A midline incision is effected between the C2 and T1 levels. Subperiosteal dissection of the ligamentum nuchae and the paracervical muscles from the spinous processes and laminae of C3-C7 is accomplished, sparing the muscular attachments to $\mathrm{C} 2$ and T1. To avoid denervation of the erector spinae muscles, the retractors should be intermittently released. A laminectomy usually extends two levels above and below the site of maximal cord compression. Bilateral troughs are created medial to the facet joints on either side after removing $1 / 2$ of the respective spinous processes (Figures 3 and 4). The outer cortex of the laminae is removed while the inner cortex is thinned to $1-2 \mathrm{~mm}$ with sequentially slower drills employing $4 \mathrm{~mm}$ diamond bits only. Removal of the remaining 1$2 \mathrm{~mm}$ may be accomplished with a 1-2 $\mathrm{mm}$ Kerrison punch or the diamond drill if hypertrophied yellow ligament is visualized directly underlying the bone to be removed. This helps avoid inadvertent perforation of an often atretic dura. Medial facetectomy (25\%) and foraminotomy are accomplished bilaterally utilizing a 


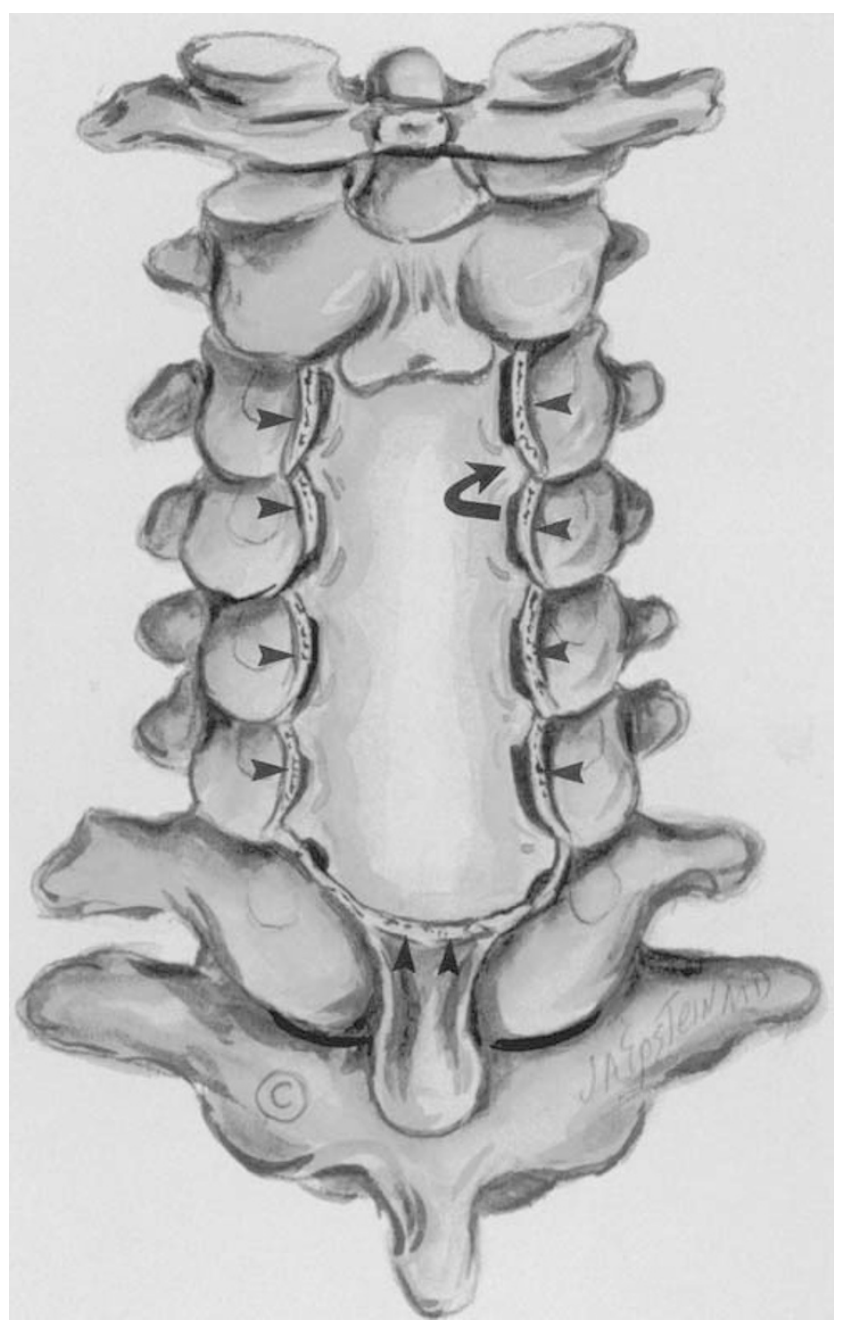

Figure 3 Laminectomy accompanied by medial facetectomy and foraminotomy (curved arrows) involves the C3-C6 levels (single arrows) with undercutting of the inferior $\mathrm{C} 7$ lamina particularly in the midline (double arrows)

$45^{\circ}$ angled, $2 \mathrm{~mm}$ rotating Kerrison rongeur. ${ }^{17}$ Undecutting of the adjacent $\mathrm{C} 2$ and $\mathrm{T} 1$ laminae is also performed to ensure midline cephalad and caudad decompression.

Lateral disc herniation or spur removal is performed by introducing a small nerve hook parallel to the thecal sac to identify the exiting nerve root. Next, a small down-biting curette may excise the sequestrated fragment or be used to cut down the spur. EMG monitoring during this portion of the operation helps warn of impending root injury in the course of dissection.

Postoperatively, a hard cervical collar is employed for up to 6 weeks following a cervical laminectomy, while a cervicothoracic orthosis may be employed in patients undergoing posterior stabilization until CT documents fusion. Postoperative MR studies readily demonstrate adequate cord decompression along with atrophic changes within the cord (Figure 5).

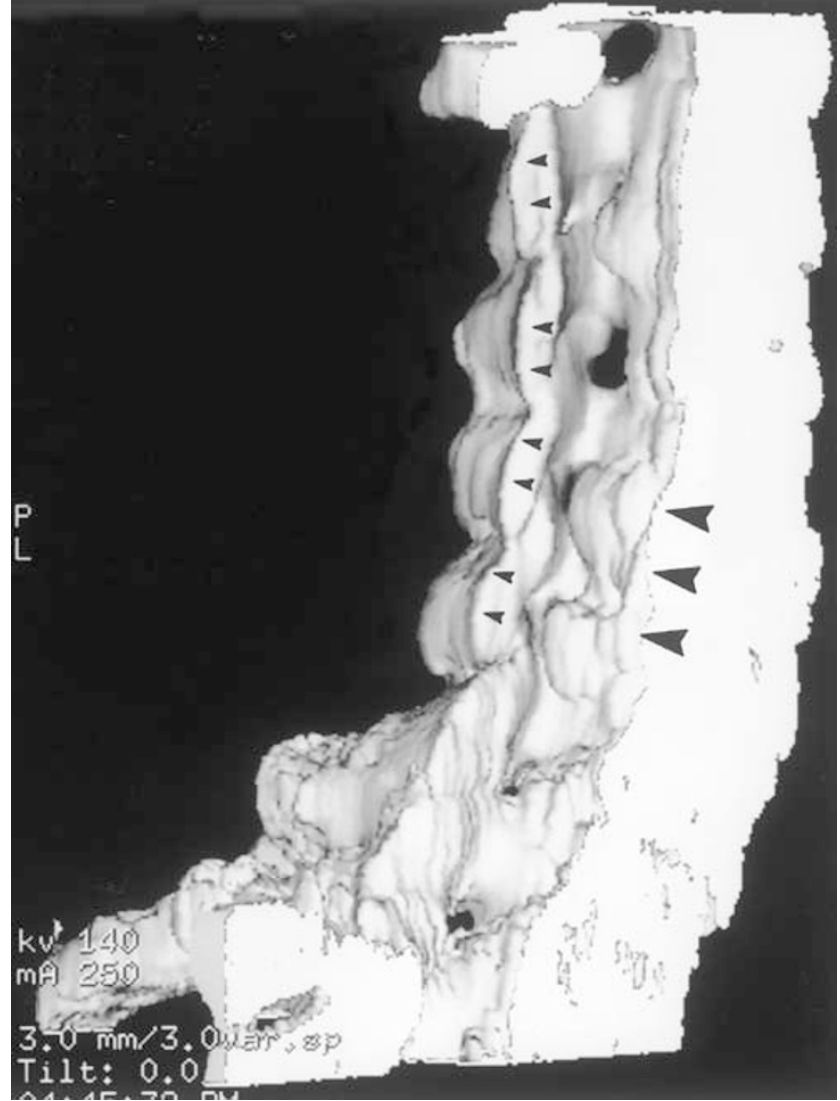

Figure 4 A 6-month postoperative 3D-CT study clearly demonstrates a moderate residual ventral bony intrusion in the lower cervical canal (triple arrows), while clearly defining the adequacy of the lateral margins of the bony laminectomy defect (double arrows)

\section{Laminoforaminotomy}

Laminoforaminotomy alone or in combination with laminectomy may be utilized to approach spondylotic spur formation or herniated discs. ${ }^{1,40}$ Zeidman and Ducker $^{41}$ performed 172 of these procedures, and demonstrated the efficacy of the laminoforaminotomy for the management of monoradicular syndromes without fusion. ${ }^{41}$ When performed at the cervico-thoracic junction, such procedures may warrant simultaneous fusion. ${ }^{40}$ More recently, Adamson's ${ }^{42}$ experience with 100 microendoscopic posterior cervical laminoforaminotomies observed excellent to good results in 97 patients with few complications being observed.

\section{Dentate section}

The dentate ligaments transmit cephalocaudal axial stresses between the spinal cord and dura, and do not 'tether' the cord either ventrally or dorsally as popularly believed. ${ }^{16}$ Therefore, intradural section of dentate ligaments will not promote cord decompression, but will unnecessarily subject patients to the risks of pneumocephalus, subdural and epidural hematoma formation, postoperative CSF fistulas, meningitis, and chronic adhesive arachnoiditis. 


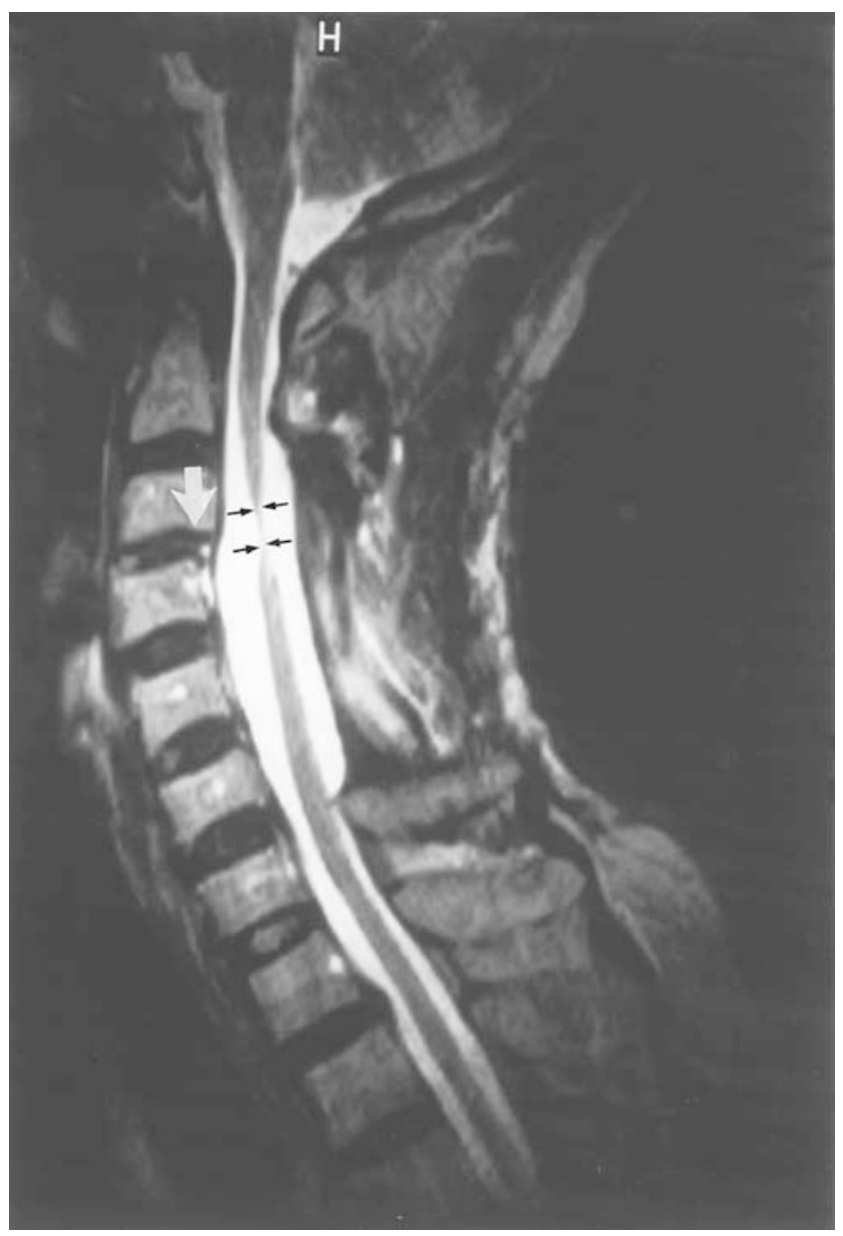

Figure 5 This T2-weighted midline sagittal MR examination, obtained 2 years following a multilevel cervical laminectomy from $\mathrm{C} 3$ to $\mathrm{C} 6$ shows significant cord atrophy (double arrows) most evident opposite the C3-C4 levels (white arrow). Preoperatively, the patient had exhibited maximal cord compression accompanied by an increased signal in the cord opposite this level

\section{Posterior stabilization}

Posterior stabilization, either performed primarily, or secondarily to address instability following failed anterior or posterior procedures, has long employed different laminar, spinous process, and facet wiring techniques. $^{22,43-45}$ For patients sustaining cervical spine trauma, $100 \%$ fusion rates were achieved using Bohlman's triple wire technique. ${ }^{44}$ For the management of pseudoarthrosis following failed anterior procedures, posterior spinous process wiring and fusion resulted in a 94\% fusion rate compared to only a $76 \%$ fusion rate for anterior reoperations. $^{43}$

Facet fusions may prevent or treat instability following laminectomy. ${ }^{11,46-48}$ Fusion occurred in $79 \%$ of Miyazaki et al's 48 patients following laminectomy, where noninstrumented facet fusions were performed. Postlaminectomy, Luque rectangle-facet fusion was successful in $90 \%$ of cases compared with a $96 \%$ fusion rate following facet wiring with a braided titanium cable. $^{43,22,44,45,47}$ With lateral mass plates, $83 \%$ of Abumi and Kaneda's ${ }^{46}$ patients undergoing laminectomy demonstrated fusion without kyphosis. Postlaminectomy fusion rates employing lateral mass plates approached $100 \%$ with limited morbidity, a $6.1 \%$ incidence of screw malposition or pullout, a $1.8 \%$ frequency of nerve root injury, and a low incidence of lateral mass fractures. $21,45,46,49,50$

Facet wiring and fusion Bilateral facet wiring and fusion provides adequate stabilization following cervical laminectomy (Figures 6-8). ${ }^{12}$ Facet joint wiring requires drilling out the articular cartilage, removing one-fourth of the superior articular facet, and careful preservation of the inferior articular facet so that the wire will not pull through as it is passed. Once the inferior articular facet is isolated, a right angle $1 \mathrm{~mm}$ dental drill is used to make a hole extending into the facet joint. A braided titanium cable is passed through this hole and may either be used to wire facet to facet in a continuous fashion or to individually wire at each level to a fibula strut allograft, which sits longitudinally along the laminectomy defect (Figure 8). ${ }^{10,51}$ Before the wire top

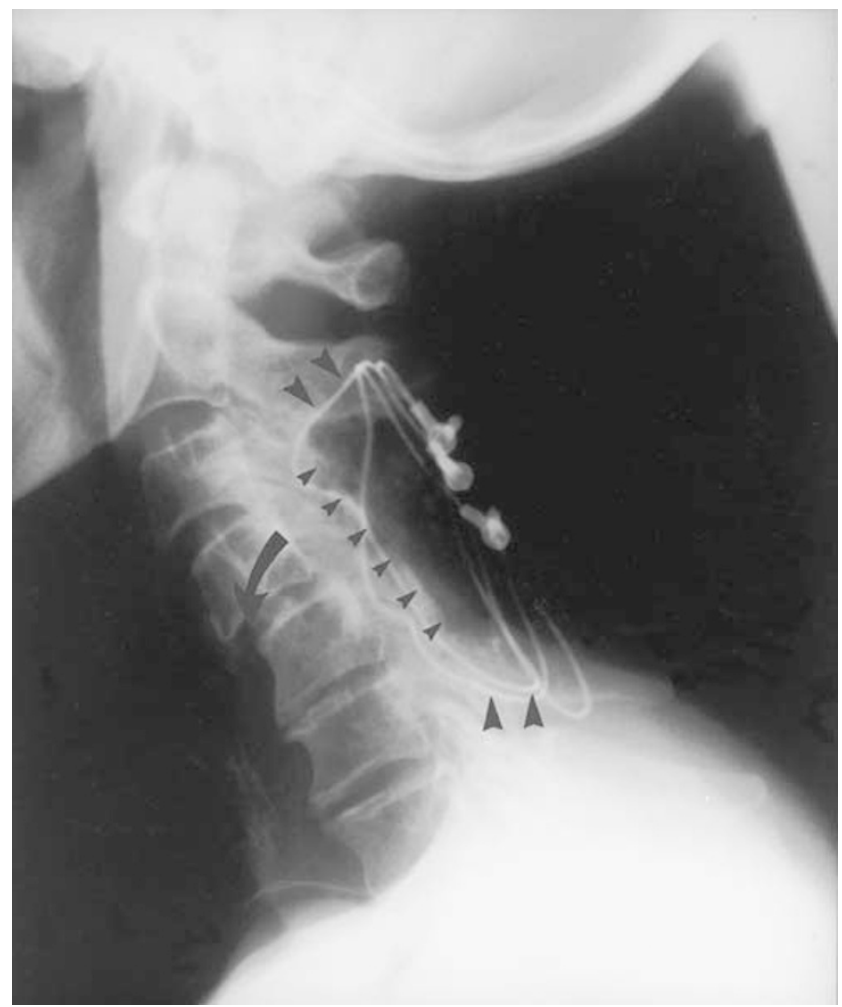

Figure 6 This 72-year-old female patient with cervical stenosis and a C4-C5 subluxation, had a C3-C5 laminectomy (six small arrows) with posterior $\mathrm{C} 2$ spinous process, $\mathrm{C} 3-\mathrm{C} 5$ facet, and $\mathrm{C} 6$ spinous process wiring and fusion performed using braided titanium cables (double arrows) and autograft bone. A 6-month postoperative extension lateral radiograph showed no increased motion at the site of preoperative olisthy (single arrow) 


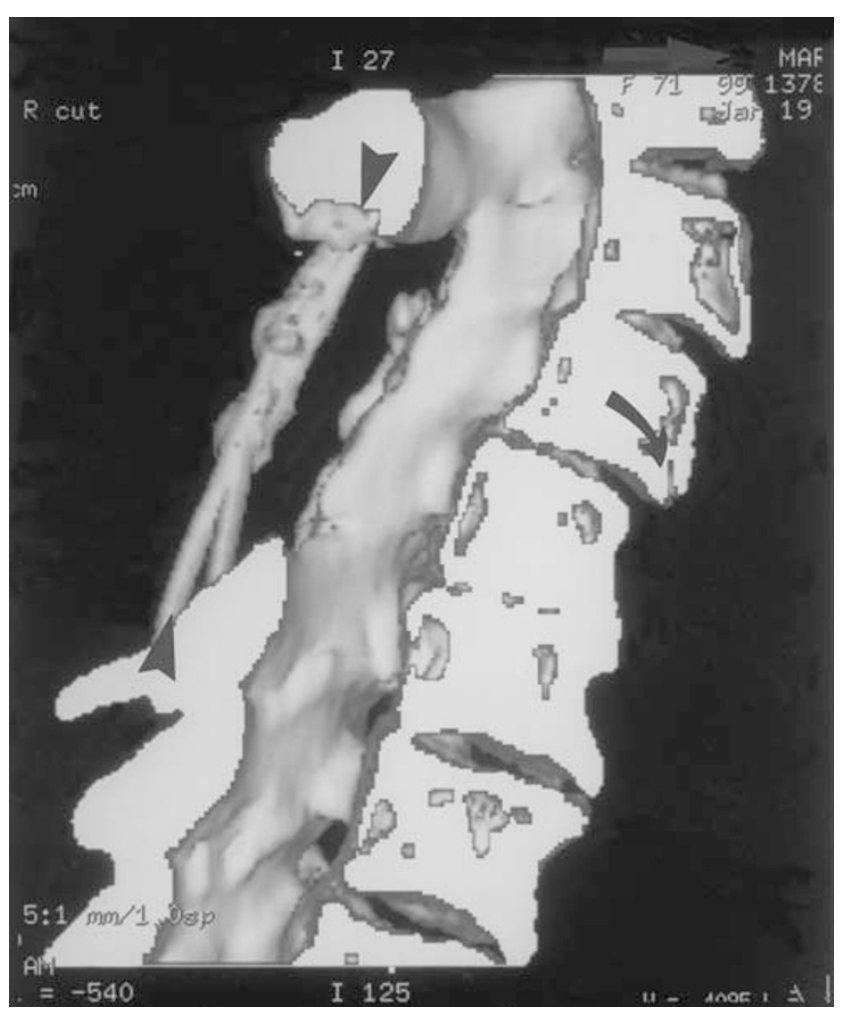

Figure 7 A 6-month postoperative midline sagittal 3D-CT examination also showed no increased olisthy opposite the $\mathrm{C4}$ $\mathrm{C} 5$ level (single arrow) and the titanium cable from $\mathrm{C} 2$ to $\mathrm{C} 6$ remained intact (double arrows). Additional parasagittal views demonstrated fusion across the $\mathrm{C} 2-\mathrm{C} 6$ facet joints

hat is crimped, autologous bone is packed into the bare facet joint and supplemented with demineralized bone matrix.

Lateral mass plates Lateral mass constructs, now using either bicortical or unicortical screws, are affixed to plates or more adjustable rod systems. The long-term efficacy of cervical laminectomy accompanied by posterior lateral mass plate placement was evaluated by Kumar et $a l^{52}$ using the Short-Form 36 questionnaire: $80 \%$ of patients experienced good outcomes, and $76 \%$ demonstrated improvement in myelopathy scores. Lateral mass plates have been applied with a relatively low complication rate. ${ }^{53}$ Of 654 screws placed in one series, complications included nerve root injury in $0.6 \%$, facet violation in $0.2 \%$, broken screws in $0.3 \%$, screw avulsion in $0.2 \%$, and screw loosening in $1.1 \% .{ }^{50}$ Other complications observed included cord injury $(2.6 \%)$, iatrogenic foraminal stenosis $(2.6 \%)$, broken plates $(1.3 \%)$, loss of reduction $(2.6 \%)$, adjacent segment degeneration $(3.8 \%)$, infection $(1.3 \%)$, and pseudarthrosis $(1.4 \%)$.

Pedicle screw fixation Pedicle screw fixation techniques offer another alternative for fusion following laminect-

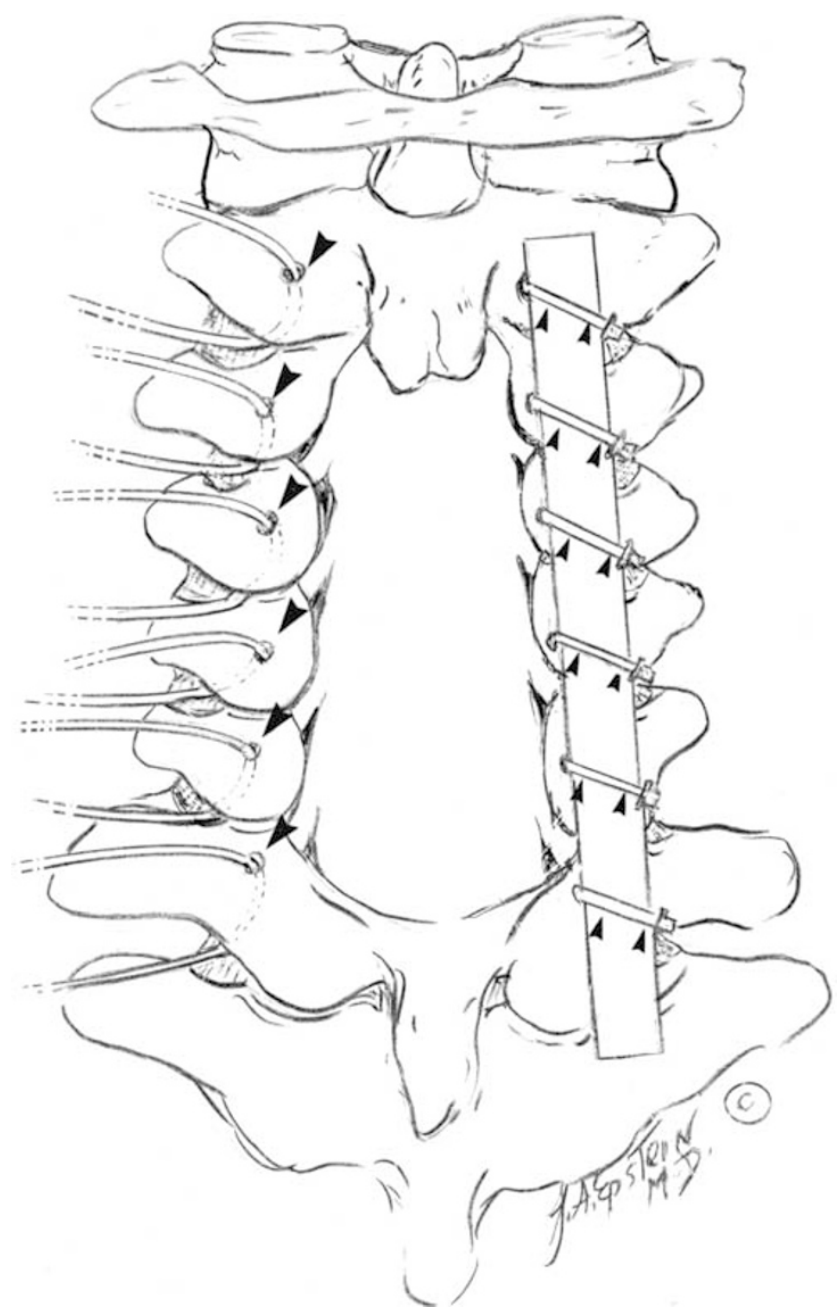

Figure 8 Illustration of a multilevel facet wiring and fusion following a C3-C6 cervical laminectomy, requiring the placement of a braided titanium cable (single arrows) through the inferior articular facets of the $\mathrm{C} 2-\mathrm{C} 7$ lamina, followed by passing each cable through a hole created in a split fibula allograft (double arrows). After the facet joints are packed with autologous bone and demineralized bone matrix, the cable may then be hand-tightened and crimped at each respective level

omy. ${ }^{46,54}$ When Abumi et al, ${ }^{54}$ used a one-stage posterior decompression and reconstructive technique for the management of 46 patients with CSM and OPLL, 5.3\% of screws perforated the cortex of the pedicles risking neurovascular injury. ${ }^{54}$

In the cervical spine, neither lateral mass or pedicle screw techniques are Federal Drug Administration (FDA) approved in the United States. For example, the disclaimer issued with the Vertex system (Sofamor Danek, Memphis, TN, USA) specifically limits its use to the upper thoracic spine (T1-T3). Despite the lack of FDA approval, these devices are commonly used by many spine surgeons who consider these devices to be part of the 'standard of care'. Nevertheless, when a suit is brought against a spine surgeon for utilizing this 
device, the lack of FDA approval serves as a 'red flag', which markedly increases the likelihood of a plaintiff's verdict and size of the award or settlement. Presently, there is a medical malpractice crisis in the United States where neurosurgeons pay up to $\$ 160,000-\$ 250,000$ for coverage, and rates for orthopedists continue to rise. Therefore, although a spine surgeon may prefer to utilize lateral mass or pedicle screw techniques for posterior cervical fusions, they markedly increase their malpractice exposure and susceptibility to successful plaintiff's litigation in the event of an untoward result.

\section{Complications of laminectomy}

Spinal cord and nerve root injuries vary from $0 \%$ to beyond $10 \%{ }^{35,55}$ Yonenobu et al, ${ }^{55}$ observed a $5.5 \%$ incidence of new cord and nerve root injuries (predominantly involving the C5 root) following 204 anterior procedures, 85 laminectomies, and 95 laminoplasties. Rapid cord migration following anterior or posterior surgery rather than direct operative trauma may contribute to immediate or delayed radicular deficits. Looking at the frequency of postoperative radiculopathy following 287 cervical laminectomies, Dai et al, ${ }^{56}$ observed that $37(12.9 \%)$ patients exhibited new postoperative root deficits involving the C5 and C6 nerve roots. To avoid such deficits following anterior cervical procedures, Saunders et $a l^{35}$ recommended limiting the ventral troughs to $15 \mathrm{~mm}$ in diameter.

Postlaminectomy kyphosis in Kaptain et $a l^{57}$ series was observed $21 \%$ of the time, but did not correlate with postoperative deterioration. Progressive kyphosis, following laminectomy observed in $47 \%$ of the patients in Kato et $a l^{58}$ series, also did not correlate with more adverse neurological outcomes.

However, when calculating the morbidity of performing laminectomy with fusion versus laminoplasty following dorsal decompressions, Heller et al, ${ }^{59}$ observed a lower complication rate and higher degree of functional improvement for laminoplasty. Nevertheless, although matched cohorts were employed to perform this study, the presence of only 13 patients in each treatment group limits the validity of the conclusions.

Management of Durotomy Cerebrospinal dural tears may be directly sutured or stapled with microdural staplers. Additionally dural grafts and muscular flaps may be applied, followed by the placement of graft matrix and fibrin sealant.

\section{Outcomes following laminectomy}

Myelopathic individuals over 65 years of age do well in the short-term but not long-term following laminectomy. ${ }^{60}$ Ebersold et al, ${ }^{61}$ found that acute postoperative neurological improvement rates were comparable following both laminectomy (68\%) and anterior surgical procedures $(72 \%)$. Even short-term reoperation rates were similar after laminectomy (13.7\%) and anterior surgery $(12 \%)$. However, the incidence of delayed deterioration (average 7.35 years postoperatively) was significantly higher following laminectomy $(10 \%)$ used more often in older individuals with high comorbid status as compared with anterior surgery $2 \%$. Similar findings were recounted in Kato et $a l^{58}$ series where patients, followed an average of 14 years following laminectomy, exhibited a $23 \%$ incidence of delayed deterioration. Although 1-year (44\%) and 5-year recovery rates $(43 \%)$ were maintained, showing no evidence of short-term deterioration, significant worsening occurred between 5 and 10 years postoperatively (33\%). Factors correlated with increased deterioration included age over 70 at the time of the first surgery, severe original myelopathy, and recent trauma.

\section{Laminectomy for central cord syndrome}

The role for delayed laminectomy to treat central cord syndromes in stenotic patients remains unproven. When Levi et $a l^{62}$ performed laminectomy 17 days following trauma-related central cord syndromes, only 12 of 20 patients improved, while seven were unchanged and one deteriorated.

\section{Laminoplasty}

Some consider laminoplasty an alternative to laminectomy or laminectomy with posterior stabilization. ${ }^{13}$ The typical laminoplasty involves removal of the ventral and dorsal cortex of the lamina on one side just medial to the facet joints, while on the opposite side, only the dorsal cortex is removed. A 'green-stick' fracture based on the hinged side is then completed, allowing the lamina to be elevated away from the underlying cord. Various techniques have subsequently evolved to 'keep the door open'. When Kohno et al ${ }^{63}$ performed laminoplasty for cervical spondylotic myelopathy and/or OPLL, they noted that 18 of 22 patients improved. Poor prognostic factors in this and other studies included age over $60-70$ years, long symptom duration ( $>18$ months), trauma, severe cord compression, kyphosis, a high signal in the cord on T2-weighted MR scans, cord atrophy, and sphincteric complaints. ${ }^{63,64}$ Biomechanical evaluation in laminoplasty versus laminectomy in a goat model, Baisden et $a l,{ }^{65}$ found that laminoplasty was superior to laminectomy in avoiding postoperative deformity.

Outcomes following laminoplasty, laminectomy and anterior surgery Dorsal decompression of any type correlates with more rapid progression of OPLL. Comparing laminoplasty (25 patients) and laminectomy (16 patients) patients with those treated without surgery (56 patient), Takatsu et al, ${ }^{66}$ found that OPLL grew more rapidly in the dorsally operated groups. Patients undergoing anterior surgery showed greater neurological recovery than those having laminectomy or laminoplasty. ${ }^{4,6-10,67}$ Kawano et al, ${ }^{67}$ noted a $78 \%$ improvement rate following anterior surgery (14 patients) versus 
a lower $46 \%$ improvement rate after laminoplasty or laminectomy (61 patients).

\section{Anterior corpectomy with fusion and posterior stabilization for $O P L L$}

Multilevel anterior corpectomy with fusion and posterior stabilization procedures performed without plates, with fixed plates, and newly introduced dynamic plates, readily address multisegmental OPLL in younger patients. ${ }^{4-10,51,68}$ In Epstein's original series of 22 nonplated severely myelopathic patients, circumferential surgery resulted in significant neurological improvement (+3 Nurick Grades), but three acute graft extrusions required emergent reoperations. ${ }^{9}$ Subsequently, 22 patients with similar pathology had a fixed plate/fixed screw system applied during comparable circumferential operations; they too markedly improved neurologically, although two exhibited subacute (6 weeks) plate-related failures with one patient ultimately requiring plate removal 6 months later for persistent dysphagia. ${ }^{10}$ Another 16 patients having a fixed plate/variable screw system applied during these multilevel constructs showed marked resolution of myelopathy, but three developed subacute (6 weeks) plate extrusions requiring urgent reoperations. ${ }^{51}$ More recently, 26 patients undergoing multilevel circumferential operations employing dynamic ABC plates (Aesculap, Tuttlingen, Germany) have improved to a Nurick Grades 0-I status (radiculopathy, mild myelopathy), with 25 successfully fusing, and only one showing a delayed pseudarthrosis warranting repeated posterior fusion. ${ }^{51}$

\section{References}

1 Epstein JA, Epstein NE. The surgical management of cervical spinal stenosis, spondylosis, and myeloradiculopathy by means of the posterior approach. In: Clark CR (ed). The Cervical Spine Research Society Editorial Committee (Ed). The Cervical Spine. 2nd edn. JB Lippincott: Philadelphia 1989, pp 625-643.

2 Brieg A, Turnbull I, Hassler O. Effects of mechanical stresses on the spinal cord in cervical spondylosis: a study of fresh cadaver material. J Neurosurg 1996; 25: 45-48.

3 Ono K, Ota H, Tada K, Yamamoto T. Cervical myelopathy secondary to multiple spondylotic protrusions: a clinicopathologic study. Spine 1977; 2: 109-125.

4 Banerji D et al. Corpectomy for multi-level cervical spondylosis and ossification of the posterior longitudinal ligament. Neurosurg Rev (Germany) 1997; 20: 25-31.

5 Epstein NE. Ossification of the posterior longitudinal ligament: diagnosis and surgical management. Neurosurg $Q$ 1992; 2: 223-241.

6 Epstein NE. The surgical management of ossification of the posterior longitudinal ligament in 51 patients. $J$ Spinal Disord 1993; 6: 432-454.

7 Epstein NE. The surgical management of ossification of the posterior longitudinal ligament in 43 North Americans. Spine 1994; 19: 664-672.

8 Epstein NE. Advanced cervical spondylosis with ossification into the posterior longitudinal ligament and resultant neurological sequelae. J Spinal Disord 1996; 9: 477-484.

9 Epstein NE. Circumferential surgery for the management of cervical ossification of the posterior longitudinal ligament. J Spinal Disord 1998; 11: 200-207.

10 Epstein NE. The value of anterior cervical plating in preventing vertebral fracture and graft extrusion following multilevel anterior cervical corpectomy with posterior wiring/fusion: indications, results, and complications. J Spinal Disord 2000; 13: 9-15.

11 Epstein NE et al. Coexisting cervical and lumbar stenosis: diagnosis and management. Neurosurgery 1984; 15: 489-496.

12 Hamanishi C, Tanaka S. Bilateral multilevel laminectomy with or without posterolateral fusion for cervical spondylotic myelopathy: relationship to type of onset and time until operation. J Neurosurg 1996; 85: 447-451.

13 Hirabayashi K, Bohlman H. Multilevel cervical spondylosis. Laminoplasty versus anterior decompression. Spine 1995; 10: 1732-1734.

14 Burgerman R et al. The association of cervical spondylosis and multiple sclerosis. Surg Neurol 1992; 38: 265-270.

15 Epstein NE. Simultaneous cervical diffuse idiopathic skeletal hyperostosis and ossification of the posterior longitudinal lament resulting in dysphagia or myelopathy in two geriatric North Americans. Surg Neurol 2000; 53: 427-431.

16 Reed JD. Effects of flexion-extension movements of the head and spine upon the spinal cord and nerve roots. J Neurol Neurosurg Psychiatry 1960; 23: 214-216.

17 Raynor RB, Pugh J, Shapiro I. Cervical facetectomy and its effect on spine strength. J Neurosurg 1985; 63: 278-282.

18 Coe JD, Warden KE, Sutterlin III CE, McAfee PC. Biomechanical evaluation of cervical spinal stabilization methods in human cadaveric model. Spine 1989; 14: $1122-1131$.

19 Cooper PR. Posterior stabilization of the cervical spine. Clin Neurosurg 1993; 40: 286-320.

20 Graham AW et al. Posterior cervical arthrodesis and stabilization with a lateral mass plate. Clinical and computed tomographic evaluation of lateral mass screw placement and associated complications. Spine 1996; 12: 323-328.

21 Grubb MR et al. Biomechanical evaluation of posterior cervical stabilization after a wide laminectomy. Spine 1997; 22: $1948-1954$.

22 Lovely TJ, Carl A. Posterior cervical spine fusion with tension-band wiring. J Neurosurg 1995; 83: 631-635.

23 Zdeblick TA et al. Cervical stability after foraminotomy. A biomechanical in vitro analysis. J Bone Joint Surg 1992; 74: 22-27.

24 Yamazaki A et al. Morphologic limitation of posterior decompression by midsagittal splitting method for myelopathy caused by ossification of the posterior longitudinal ligament in the cervical spine. Spine 1999; 24: 32-34.

25 Ishida Y, Ohmori K, Suzuki K, Inoue H. Analysis of dural configuration for evaluation of posterior decompression in cervical myelopathy. Neurosurgery 1999; 44: 91-95.

26 Al-Mefty $\mathrm{O}$ et al. Myelopathic cervical spondylotic lesions demonstrated by magnetic resonance imaging. J Neurosurg 1988; 68: 217-222.

27 Matsuda Y et al. Increased MR signal intensity due to cervical myelopathy. Analysis of 29 surgical cases. J Neurosurg 1991; 74: 887-892. 
28 Okada Y et al. Magnetic resonance imaging study on the results of surgery for cervical compressive myelopathy. Spine 1993; 18: 2024-2029.

29 Morimoto T, Ohtsuka H, Sakaki T, Kawaguchi M. Postlaminectomy cervical spinal cord compression demonstrated by dynamic magnetic resonance imaging. Case report. J Neurosurg (US) 1998; 88: 155-157.

30 Nelson BW et al. Can spinal surgery be prevented by aggressive strengthening exercises? A prospective study of cervical and lumbar patients. Arch Phys Med Rehabil (US) 1999; 80: 20-25.

31 Nakamura $\mathrm{K}$ et al. Conservative treatment for cervical spondylotic myelopathy: achievement and sustainability of a level of 'no disability'. J Spinal Disord (US) 1998; 11: 175-179.

32 Persson LC, Carlsson CA, Carlsson JY. Long-lasting cervical radicular pain managed with surgery, physiotherapy, or a cervical collar. A prospective, randomized study. Spine 1997; 22: 751-758.

33 Saal JS, Saal JA, Yurth EF. Nonoperative management of herniated cervical intervertebral disc with radiculopathy. Spine (US) 1996; 21: 1877-1883.

34 Matsumoto $\mathrm{M}$ et al. Increased signal intensity of the spinal cord on magnetic resonance imaging in cervical compressive myelopathy. Does it predict the outcome of conservative treatment? Spine 2000; 25: 77-82.

35 Saunders RL, Pikus HJ, Ball P. Four-level cervical corpectomy. Spine 1998; 23: 2455-2461.

36 Epstein NE, Danto J, Nardi D. Somatosensory evoked potential monitoring during 100 cervical operations. Spine 1993; 18: 737-747.

37 Albin MS, Carroll RG, Maroon JC. Clinical considerations concerning detection of venous air embolism. Neurosurgery 1978; 3: 380-384.

38 Matjasko J, Petrozza P, Cohen M, Steinberg P. Anesthesia and surgery in the seated position: analysis of 554 cases. Neurosurgery 1985; 17: 695-702.

39 Standefer M, Bay JW, Trusso R. The sitting position in neurosurgery: a retrospective analysis of 488 cases. Neurosurgery 1984; 14: 649-658.

40 Epstein NE. Technical Note: unilateral posterior resection of cervical disc and spondylostenosis with contralateral fusion for instability. Surg Neurol (US) 2001; 56: 256-258.

41 Zeidman SM, Ducker TB. Posterior cervical laminoforaminotomy for radiculopathy: review of 172 cases. Neurosurgery 1993; 33: 356-362.

42 Adamson TE. Microendoscopic posterior cervical laminoforaminotomy for unilateral radiculopathy: results of a new technique in 100 cases. $J$ Neurosurg (US) 2001; 95(1 Suppl): 51-57.

43 Brodsky AE, Khalil MA, Sassard WR, Newman BP. Repair of symptomatic pseudarthrosis of anterior cervical fusion. Posterior versus anterior repair. Spine 1992; 17: 137-143.

44 Weiland DJ, McAfee PC. Posterior cervical fusion with triple-write strut graft techniques; one hundred consecutive patients. J Spinal Disord 1991; 4: 15-21.

45 Weiss JC et al. In vitro biomechanical comparison of multistrand cables with conventional cervical stabilization. Spine 1996; 21: 2108-2114.

46 Abumi K, Kaneda K. Pedicle screw fixation for non traumatic lesions of the cervical spine. Spine 1997; 22: 1853-1863.
47 Maurer PK et al. Cervical spondylotic myelopathy: treatment with posterior decompression and Luque rectangle bone fusion. Neurosurgery (US) 1991; 28: 680-683.

48 Miyazaki K et al. Posterior extensive simultaneous multisegment decompression with posterolateral fusion for cervical myelopathy with cervical instability and kyphotic and/or S-shaped deformities. Spine 1989; 14: 1160-1170.

49 Ebraheim NA, Rupp RE, Salvolaine ER, Brown JA. Posterior plating of the cervical spine. J Spinal Disord 1995; 8: $111-115$.

50 Heller JG, Silcox III DH, Sutterline III CE. Complications of posterior cervical plating. Spine 1995; 20: 2442-2448.

51 Epstein NE. Anterior approaches to cervical spondylosis and ossification of the posterior longitudinal ligament: review of operative technique and assessment of 65 multilevel circumferential procedures. Surg Neurol 2001; 55: $313-324$.

52 Kumar VG, Rea GL, Mervis LJ, McGregor JM. Cervical spondylotic myelopathy: functional and radiographic longterm outcome after laminectomy and posterior fusion. Neurosurgery 1999; 44: 771-777.

53 Wellman BJ, Follett KA, Traynelis VC. Complications of posterior articular mass plate fixation of the subaxial cervical spine in 43 consecutive patients. Spine 1998; 23: 193-200.

54 Abumi K, Kaneda K, Shono Y, Fujiya M. One-stage posterior decompression and reconstruction of the cervical spine by using pedicle screw fixation systems. J Neurosurg 1999; 90(1 Suppl): 19-26.

55 Yonenobu K et al. Neurologic complications of surgery for cervical compression myelopathy. Spine 1991; 16: 1277-1282.

56 Dai L, Ni B, Yuan W, Jia L. Radiculopathy after laminectomy for cervical compression myelopathy. $J$ Bone Joint Surg (Br) 1998; 80: 846-849.

57 Kaptain GJ, Simmons NE, Replogle RE, Pobereskin L. Incidence and outcome of kyphotic deformity following laminectomy for cervical spondylotic myelopathy. J Neurosurg (US) 2000; 92(2 Suppl): 199-204.

58 Kato $\mathrm{Y}$ et al. Long-term follow-up results of laminectomy for cervical myelopathy caused by ossification of the posterior longitudinal ligament. J Neurosurg 1998; 89: 217-223.

59 Heller JG, Edwards CC, Murakami H, Rodts GE. Laminoplasty versus laminectomy and fusion for multilevel cervical myelopathy: an independent matched cohort analysis. Spine 2001; 26: 1330-1336.

60 Snow RB, Weiner H. Cervical laminectomy and foraminotomy as surgical treatment of cervical spondylosis: a follow-up study with analysis of failures. $J$ Spinal Disord 1993; 6: $245-250$.

61 Ebersold MJ, Pare MC, Quast LM. Surgical treatment for cervical spondylotic myelopathy. J Neurosurg 1995; 82: 745-751.

62 Levi L et al. The significance of dorsal migration of the cord after extensive cervical laminectomy for patients with traumatic central cord syndrome. J Spinal Disord 1995; 8: 289-295.

63 Kohno K et al. Evaluation of prognostic factors following expansive laminoplasty for cervical spinal stenotic myelopathy. Surg Neurol 1997; 48: 237-245.

64 Lee TT, Manzano GR, Green BA. Modified open-door cervical expansive laminoplasty for spondylotic myelopathy: operative technique, outcome, and predictors for gait improvement. J Neurosurg 1997; 86: 64-68. 
65 Baisden $\mathbf{J}$ et al. Evaluation of cervical laminectomy and laminoplasty. A longitudinal study in the goat model. Spine (US) 1999; 24: 1283-1288.

66 Takatsu T, Ishida Y, Suzuki K, Inoue H. Radiological study of cervical ossification of the posterior longitudinal ligament. J Spinal Disord 1999; 12: 271-273.
67 Kawano $\mathrm{H}$ et al. Surgical treatment for ossification of the posterior longitudinal ligament of the cervical spine. J Spinal Disord 1995; 8: 145-150.

68 Sonntag VK, Herman JM. Reoperation of the cervical spine for degenerative disease and tumor. Clin Neuorsurg (US) 1992; 39: 244-269. 